\title{
Consumer Personality, Privacy Concerns and Usage of Location-Based Services (LBS)
}

\author{
Soo Shen Hin, Tan Ka Yen Madeline Tanamal, Ho Ju Yi, Low Wen Ling, Maryam Muhammed Yahya, \\ and Jessica Sze Yin Ho*, Member, IEDRC
}

\begin{abstract}
This paper examines the effects of the Big Five personality traits on concern for information privacy (CFIP) and the effects of the formulated concern for information privacy towards perceived risk, which in turn determine location-based services (LBS) usage intention. Data for this research was collected from 291 users and non-users of LBS. Result from Pearson correlation analysis indicated significant relationships exist between: (1) extraversion, and openness with collection; (2) extraversion, conscientiousness, and openness with improper access; (3) extraversion, conscientiousness, and openness with errors; (4) agreeableness, neuroticism, and openness with secondary use. All four dimensions of CFIP are found to have a significant direct relationship with perceived risk of using LBS. Implications for research and practice for location-based service providers are discussed.
\end{abstract}

Index Terms - Information Privacy, Consumer Behaviour, Location-Based Services (LBS), Digital-marketing

\section{INTRODUCTION}

The rise of internet connectivity and m-commerce have boost the use Location-based Services (LBS) applications for mobile communication devices. LBS allow customization of advertisements or information based on consumer profiles, within the context of geographical awareness of consumer movement [1]. LBS usage is arguably more effective to boost sales due to its instantaneous "right there, right now" nature $[1,2,3]$. To consumers, LBS offer much benefits, convenience, flexibility and even social connection to users [3]. However, despite perceived usefulness of LBS, it may raise concerns of businesses invading upon the personal and private space of consumers, for example personal information being exposed or leaked to unauthorized third parties [1]. The feeling of being track and their privacy violated lead to perceived risk of LBS by consumers that eventually affects the consumer intention to use LBS.

As it is imperative for corporations and business organisations to understand the concept of privacy concerns from the perspective of consumers, the industrial practitioners are in dire need of research and recommendations encompassing this matter. Also, as alluded by Korzaan and Boswell [4], limited research has been conducted in examining the influence of personality traits towards technology aspects in terms of privacy concerns and usage intentions. This research build upon the recommendation of Junglas, Johnson and Spitzmüller [5] to conduct the study of Big Five personality traits, namely extraversion, agreeableness, conscientiousness, neuroticism and openness to experience as antecedents of information privacy concern when LBS are finally commercially available. At the same

Manuscript received January 28, 2014. time it will contribute to expand the research model of Zhou [1] by including personality traits as an antecedent of concern for information privacy in the context of LBS usage intentions.

This emerging field of study is prime for research given that LBS utilise geographically-sensitive information regarding the consumer, and questions arise as to how privacy concerns are formulated within this type of scenario. Specifically, do individual differences in terms of personality traits influence the formulation of concern for information privacy? Subsequently, will concern for information privacy affect consumers perceived risk when using LBS? The value of this research is also in extending the knowledge base regarding information privacy in terms of determining antecedents of information privacy concerns and the resulting outcomes.

\section{LITERATURE REVIEW}

\section{A. Location-Based Services}

Location-based services can be best defined as, "any service that takes into account the geographic location of an entity" [5].The location of a person or an object is used to shape or as a focus on LBS application [6]. LBS rely on either mobile networks, satellite navigation system or local positioning system [7]. Its applications come in a form of mobile navigation, location-based advertisements, mobile social network check-in services, and emergency tracking [1]. LBS technology can help businesses to customised information and communications towards consumers, and this would enrich the consumer experience by giving specific offerings that cater to individual preferences. It collects information about behaviour, preferences, beliefs and additional knowledge through the system that can be of great value to organization [8].

Shin et al. [9] justified that LBS are increasing in functionality, with examples including searching for nearby restaurants based on current location and even finding timely discounts or coupons for retail outlets in the immediate vicinity but such geographical information can be sensitive as lifestyle habits, travelling patterns and the living residence address can be discerned. Despite its apparent usefulness, there are possible hazards of LBS, which include unconsented resale of consumer information and breach as well as exposure of consumer information databases [10]. It also brings about more serious consumer privacy concerns compared to other mobile applications due to its automated manner of collecting information [11]. Privacy issue in Permission-based mobile advertising (PBMA) is regarded as simplest to tackle (Godin [12] cited by Bamba \& Barnes [2]). 


\section{B. Concern for Information Privacy (CFIP)}

The concept of information privacy within the context of consumer transactions with businesses emerged with the advent of electronic commerce. Pavlou [13] summarises that concern for information privacy refers to irresponsible use of personal information, dissemination of personal information to external parties and secondary usage of personal information without consent or permission. A commonality between the various views is that privacy concern impinges upon notions of access and usage of personal information, consumer awareness and permission to use that information.

Seminal research by Smith, Milberg and Burke [14] resulted in the development of a valid measurement instrument that reflected individual privacy concerns with regards to organization privacy practices along four dimensions which are collection, improper access, errors and secondary use. Stewart and Segars [15] later re-validated and refined CFIP. Collection is a concern related to the huge amount of personal information that is collected and stored in company's database. Improper access is a concern that the collected information becomes accessible to unauthorized people. Errors concern are that information may become incorrect and tainted due to unintentional or malicious alterations. Secondary use is a concern for how collected personal information is used, either by internal or external party of the organization, or for other purpose other than initial intention. After an extensive interdisciplinary review of past information privacy research, Smith, Dinev and $\mathrm{Xu}$ [16] concluded that the dimensions used in the CFIP model are considered some of the most reliable scales in determining concerns towards privacy practices of organisations. Due to the reliability of CFIP and the nature of LBS (IT applications), CFIP model will be used in this research.

\section{HYPOTHESIS DEVELOPMENT \& RESEARCH FRAMEWORK}

\section{A. Big Five Personality Traits and CFIP}

Past research has highlighted information privacy concerns to be a multidimensional construct that spans from the individual levels of analysis to societal levels of analysis [17]. As LBS is an emerging field of study, a good starting point may be from the perspective of individual privacy concerns. Moreover, LBS applications are customised to meet consumers' need. At the individual level, information privacy concern is linked with the Big Five personality traits, representing integral components in studying how people process information, form attitudes and derive behaviour [18]. Personality traits determined the degree of intensity of attitudinal constructs (Maddux, and Rogers [19]; cited by Junglas et al. [5]). Li [17] contends that based on individual personality theories, the various personality traits may to some extent have an effect on personal cognitive functions and the resulting behavior.

There is evidence from other researchers that personality traits can be an important factor to consider when studying the usage intention of consumers towards LBS. Juglas et al. [5] found that among the Big Five personality traits, conscientiousness, agreeableness and openness influenced information privacy concern while neuroticism and extraversion did not influence information privacy concern. Hirsh, Kang, and Bodenhausen [20] found that LBS pervasiveness vary with personality traits. LBS can be tailor-made to specifically cater to individuals of varying personalities, allowing for greater congruence of the advertisement relevance and personality characteristics [20]. A dearth of research mentioned that adoption of new technologies is influenced by individual differences and personality characteristics [11], hence the need for such research. Similarly, we proposed that individual differences can influence one's perception of privacy towards the usage intention of LBS. All included, this research will incorporate the Big Five Personality traits into the study of CFIP. We hypothesized that:

H1.1-H1.5. Extraversion, agreeableness, conscientiousness, neuroticism and openness will have a relationship with collection.

H2.1-H2.5. Extraversion, agreeableness, conscientiousness, neuroticism and openness will have a relationship with improper access.

H3.1-H3.5. Extraversion, agreeableness, conscientiousness, neuroticism and openness will have a relationship with errors.

H4.1-H4.5. Extraversion, agreeableness, conscientiousness, neuroticism and openness will have a relationship with secondary usage.

\section{B. CFIP and Perceived Risk}

From consumers' perspective, information privacy concern includes both the concern for security of personal information as well as how it is acted upon in terms of transmission and dissemination [7]. Choi and Choi [11] found that the more user have their own privacy concerns, the less likely they use Location Based Services. Perceived risk is viewed as a multidimensional construct based on four factors which are financial risk, psychological risk, performance risk and social loss [21]. Giovanis, Binioris and Polychronopoulos [22] develop this understanding further to include losing control over monetary assets and time as well as the looming threat of service provider system failure. Problems arises when the users with high privacy concern and perceives a risk connected to the usage of LBS.

Although LBS has been adopted by many businesses today, the collection and dissemination of personal information by service providers can affect user's usage intention as they may be gathered with consent or without choice [23]. Therefore, consumers seek to provide the information solely for business transactions [24]. Many would perceive organizations to have the responsibility to ensure users that their information will be kept confidential and there is always the prospect of collected information being sold to third parties. This is viewed as a perceived risk, hence:

H5.1. Collection will have a positive relationship with perceived risk

Improper access reflects the security of information storage where authorized users can access the databases for personal information from the mobile service. Nevertheless, the problem of hackers hacking into databases is a real threat and this leads to a lack of trust and confidence in securing one's own privacy [1]. This exposed to criminal intent, known as 
hackers [8], is viewed as perceived risk by consumer. Therefore, we hypothesized that:

H5.2. Improper access will have a positive relationship with perceived risk.

Errors reflect the accuracy of personal information that is stored in the databases. When there is no verification measure to detect incorrect information this will affect the level of perceived risk [1]. Therefore, service providers need give assurance to consumers by employing suitable measures to ensure the accuracy of collected information. The perceived risk is when the information provided by consumer is maliciously modified. Hence, we hypothesized that:

H5.3. Errors will have a positive relationship with perceived risk.

Marketing practices conducted by online retailers have the probability of breaching the privacy of consumer. It may seem that if businesses employ privacy practices that are insensitive to consumer consent, such as selling consumer personal information to external third parties, consumer loyalty would be jeopardised. This is seen as a perceived risk to consumers [1]. Ratnasingham [25] confirms that privacy has significant impact on loyalty towards online retailers. Therefore, we hypothesized that:

5.4. Secondary usage will have a positive relationship with perceived risk.

\section{Perceived Risk and LBS Usage Intention}

Perceived risk is hypothesized to be a direct antecedent of intentions to use LBS [26]. Perceived risk were found to be key mediators to predict intentions to use the online store Amazon [13]. In recent work, CFIP has been investigated using Structural Equation Modelling [1], the hypothesis being that CFIP would positively affect perceived risk. Results showed that concern about collection of information, errors in information, and unauthorised secondary use affected perceived risk, which in turn determined usage of LBS. Hence, our hypothesis are:

H6. Perceived risk will have a negative relationship with usage intention.

On the existing CFIP and LBS usage research model by Zhou (2011), we incorporated personality traits as antecedent factors in influencing concern for information privacy. Our research model is reflected in Figure 1.

\section{Research Methodology}

The instrument on CFIP, perceived risk and usage intention were adapted from the research carried out by Zhou [1] on the impact of privacy concern on user adoption of LBS. The Big Five Personality instrument was adapted from research by Tsao and Chang [27] on exploring the impact of personality traits on online shopping behavior. Survey items were measured using a 7-point Likert scale ranging from 1= "Strongly Disagree" to 7= "Strongly Agree". Self-reported scales are used as it is a common measurement tool for information privacy concerns within information systems research. The sampling method used was convenience sampling which Limbu, Wolf and Lunsford [28] justifies as satisfactory in validating theory as long as they fulfill specific requirements. In this study the majority of respondents sampled through the convenience method fulfilled the requirement of being a potential LBS user and thus the sample qualifies for the research objectives.

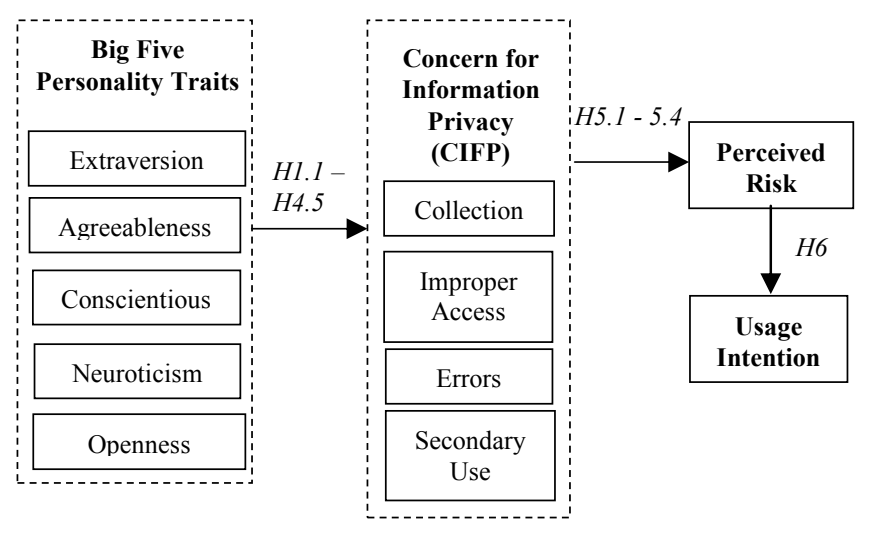

Fig. 1. Research Framework

A total of 310 questionnaires are given out using direct and online procedures, in which only 291 are usable. The targeted respondents are adults of or above 21 years old, both users and non-users of LBS in the Klang Valley. Respondents' anonymity was assured as the responses were kept private and confidential. Most of the respondents are female $55 \%$ and singles $(80.8 \%)$. Respondents can be segmented into 3 age groups, where $66.3 \%$ of the respondents were aged between $21-25$ years old, $18.9 \%$ aged between $26-30$ years old, and $14.8 \%$ were aged 31 and above. $44.3 \%$ of the respondents earned more than RM2000 a month. Approximately 57\% of the respondents are LBS users.

Date collected is subject to reliability testing. One item was deleted from the Improper Access, Perceived Risk and Neuroticism variable to meet the minimum threshold of Cronbach's Alpha 0.7 [29]. Cronbach's Alpha ranges between $0.726-0.862$ upon deleting some items (See Table 1). 13 outliers were removed from the dataset when data was checked for normality. The data recorded a standard deviation ranged of $0.922-1.507$, which is within $+/-3$ from its mean, hence the normal bell-curved shaped is assumed [30]. All the means can be considered distributed normally as kurtosis value ranged from -0.850 to 3.431 , which is within the threshold of $+/-10$ [31].

TABLE I: RELIABILITY TEST

\begin{tabular}{lcc}
\hline \hline Construct & No. of Items & Cronbach's Alpha \\
\hline Collection & 4 & 0.862 \\
Improper Access & 2 & 0.784 \\
Errors & 3 & 0.849 \\
Secondary Use & 4 & 0.866 \\
Perceived Risk & 2 & 0.767 \\
Usage Intention & 2 & 0.726 \\
Extraversion & 4 & 0.790 \\
Agreeableness & 3 & 0.824 \\
Conscientious & 4 & 0.835 \\
Neuroticism & 6 & 0.839 \\
Openness & 2 & 0.783 \\
\hline \hline
\end{tabular}




\section{FINDINGS AND DISCUSSION}

Data was analysed using Pearson correlation analysis. Contrary to expectations, the correlation results show that most personality traits had either weak or insignificant relationship with the concern for information privacy (see Table 2). Some of the significant relationships are between: (1) extraversion, and openness with collection; (2) extraversion, conscientiousness, and openness with improper access; (3) extraversion, conscientiousness, and openness with errors; (4) agreeableness, neuroticism, and openness with secondary use. This finding may imply that potential users of LBS tend to be highly conscious of how much information they actively intend to give and whether the given information reflects the truth. People who weigh heavily in agreeableness are more empathetic and compassionate and hence may be able to imagine and understand the sense of infringement of personal autonomy and awareness through the undesirable experience of having their personal information being sold to third parties.

TABLE 2: RESUlt OF HyPOTHESIS TESTING

\begin{tabular}{|c|c|c|c|}
\hline Hypothesis & Path & Correlation & $\begin{array}{c}\text { Supported/ } \\
\text { Not Supported }\end{array}$ \\
\hline H 1.1 & PT_E $\rightarrow$ C & $0.183 * *$ & Yes \\
\hline H 1.2 & $\mathrm{PT}_{-}^{-} \mathrm{A} \rightarrow \mathrm{C}$ & -0.050 & No \\
\hline H 1.3 & $\mathrm{PT}^{-} \mathrm{C} \rightarrow \mathrm{C}$ & 0.077 & No \\
\hline H 1.4 & $\mathrm{PT}_{-}^{-} \mathrm{N} \rightarrow \mathrm{C}$ & -0.063 & No \\
\hline H 1.5 & $\mathrm{PT}_{-}^{-} \mathrm{O} \rightarrow \mathrm{C}$ & $0.150 * *$ & Yes \\
\hline H 2.1 & PT_E $\rightarrow$ IA & $0.127 *$ & Yes \\
\hline H 2.2 & $\mathrm{PT}_{-}^{-} \mathrm{A} \rightarrow \mathrm{IA}$ & 0.099 & No \\
\hline H 2.3 & $\mathrm{PT}_{-}^{-} \mathrm{C} \rightarrow \mathrm{IA}$ & $0.182 * *$ & Yes \\
\hline H 2.4 & $\mathrm{PT}_{-}^{-} \mathrm{N} \rightarrow \mathrm{IA}$ & -0.113 & No \\
\hline H 2.5 & $\mathrm{PT}^{-} \mathrm{O} \rightarrow \mathrm{IA}$ & $0.157 * *$ & Yes \\
\hline H 3.1 & PT_E $\rightarrow$ E & $0.227 * *$ & Yes \\
\hline H 3.2 & $\mathrm{PT}_{-}^{-} \mathrm{A} \rightarrow \mathrm{E}$ & 0.001 & No \\
\hline H 3.3 & PT_C $\rightarrow$ E & $0.207 * *$ & Yes \\
\hline H 3.4 & PT_N $\rightarrow$ E & -0.065 & No \\
\hline H 3.5 & $\mathrm{PT} O \mathrm{O} \rightarrow \mathrm{E}$ & $0.181 * *$ & Yes \\
\hline H 4.1 & PT_E $\rightarrow$ S & 0.101 & No \\
\hline H 4.2 & $\mathrm{PT}_{-} \mathrm{A} \rightarrow \mathrm{S}$ & $0.187 * *$ & Yes \\
\hline$H 4.3$ & $\mathrm{PT}_{-}^{-} \mathrm{C} \rightarrow \mathrm{S}$ & 0.051 & No \\
\hline H 4.4 & $\mathrm{PT}_{-}^{-} \mathrm{N} \rightarrow \mathrm{S}$ & $-0.160 * *$ & Yes \\
\hline H 4.5 & $\mathrm{PT}_{-}^{-} \mathrm{O} \rightarrow \mathrm{S}$ & $0.148^{*}$ & Yes \\
\hline H 5.1 & $\mathrm{C} \rightarrow \mathrm{PR}$ & $0.354 * *$ & Yes \\
\hline H 5.2 & $\mathrm{IA} \rightarrow \mathrm{PR}$ & $0.423 * *$ & Yes \\
\hline H 5.3 & $\mathrm{E} \rightarrow \mathrm{PR}$ & $0.378 * *$ & Yes \\
\hline H 5.4 & $\mathrm{~S} \rightarrow \mathrm{PR}$ & $0.418^{* *}$ & Yes \\
\hline H 6 & $\mathrm{PR} \rightarrow \mathrm{UI}$ & $-0.247 * *$ & Yes \\
\hline
\end{tabular}

For the remaining personality traits, they have no clear discernible impact on concern for information privacy. A possible explanation could be that the effect of each personality trait was studied individually towards the CFIP, while in reality, as Junglas et al. [5] explains is that personality traits act in unison and work as a whole. Another possible explanation for the inconclusive relationship between personality traits and information privacy concerns as well as usage intention is the contextual nature of information privacy formulation. Smith, Dinev and Xu [16] also raise another important perspective by arguing that since the contextual nature of information privacy may influence the very definition and meaning of information privacy, it may also change its relationship with other constructs.

All four dimensions of CFIP are found to have almost the same significant relationship with perceived risk. This is slightly different from Zhou's [1] findings where secondary use and collection were found to have relatively larger impact on perceived risk. These results confirmed again that consumers are concerned on all dimensions of CFIP. Businesses have to be wary on all four dimensions of CFIP. The results also shows that perceived risk are significantly influencing usage intention, which is consistent with previous research by Zhou [1]. The factors of espoused privacy protection measures and perceived benefits in exchange of disclosing private information [13], as well as the type of personal information being sought after [32] also represent considerations worth noting. Among the potential users of LBS, they perceived risk, nevertheless they intend to use LBS. This linkage between perceived risk and usage of LBS is in line with Zhou [33] study. This implies that there is perceived risk in using LBS but the expected benefits of using LBS seem to outweigh the probability of any negative outcomes.

\section{IMPLICATIONS \& CONCLUSION}

Given the prominence and consistency of concern for information privacy and its influence towards perceived risk and the eventual usage intention, businesses and service providers must not take this aspect for granted and substantial resources should be dedicated towards creating robust and inclusive consumer privacy management processes that would aim to allay consumer uncertainty regarding LBS and create a mutually-beneficial and lasting business relationship with consumers. Zhou [1] also highlighted that mobile service providers should provide certification to prevent unauthorized access to user's personal information. The onus is on organizations and businesses to employ private data protection measures and safeguards that both address consumer concerns and prevent misuse of such information. Examples would include creating secure and encrypted databases to store the personal information, using privacy statements and agreements that explain the terms of usage of the personal information and that seek the consent and agreement of consumers before requesting the disclosure of personal information from consumers. Other points that businesses should take note of is that the imperative to avoid asking unnecessary questions or advertisements and repetitively asking for permission [2]. Lastly, businesses need not overly focus on customization in respect of consumers' personality traits, as only a few of the personality traits affects how their concern about information privacy. This is perhaps due to the universal appeal of convenience and personalized product and service offerings.

This study is bound by several limitations which provide the avenues for future research. Firstly, because this study uses self-disclosure survey scales that provides limited representation of the rich continuum of responses and only touch on the surface of the real reasoning and cognitive processes of respondents that are also prone to subjective interpretation, it is recommended that mixed-method data collection approach to be undertaken in the future. In addition, some researchers have noted the notions of privacy are situation and context-specific and this may differ from general concerns of privacy [34]. Hence, providing respondents with a tangible and realistic representation of possible instances of privacy breaches such as specific types of fraud would allow respondents to better conceptualise privacy instead of relying on abstract thinking. Also, this 
research is only looking into individual difference in personality traits. In reality, personality differences are one of many possible determinants for differences in privacy concerns as people differ demographically and culturally. Moving forward, research should be conducted across different cultural environments and gradually evolve from the individual level of analysis towards group and organisational levels which would recognise the effects of peer pressure and group norms. Future research should address the cumulative effect of personality traits, with each trait mutually interacting to produce a more nuanced psychological profile of a consumer and their conception of concern for information privacy.

In a nutshell, the findings from this research have reaffirmed that there are linkages between concern for information privacy and perceived risk as well as the significance of perceived risk affecting usage intention as shown in research by Zhou [1]. The rapid development of LBS offers both opportunities and challenges that would redefine the business and consumer relationship. As customer engagements become increasingly personal and attuned to individual preferences, businesses have to maintain an objective balance between deriving increased profits from this form of individualised engagement through LBS and maintaining respect for consumer rights to privacy.

\section{REFERENCES}

[1] Zhou, T., "The impact of privacy concern on user adoption of location-based services," Industrial Management \& Data Systems, vol. 111, no. 2, pp. 212-226, 2011.

[2] Bamba, F. and Barnes, S.J., "SMS Advertising, Permission and the Consumer: A Study," Business Process Management Journal, vol. 13, no. 6, pp. 815-829, 2007.

[3] Luo, X., Li, H., Zhang, J., and Shim, J. P., "Examining multi-dimensional trust and multi-faceted risk in initial acceptance of emerging technologies: An empirical study of mobile banking services," Decision Support Systems, vol. 49, no. 2, pp. 222-234, 2010.

[4] Korzaan, M. L., and Boswell, K. T., "The influence of personality traits and information privacy concerns on behavioral intentions," Journal of Computer Information Systems, 48(4), pp. 15-24, 2008.

[5] Junglas, I. A., Johnson, N. A., and Spitzmüller, C., "Personality traits and concern for privacy: an empirical study in the context of location-based services," European Journal of Information Systems, vol. 17, no. 4, pp. 387-402, 2008.

[6] Duri, S., Cole, A., Munson, J., and Christensen, J., “An approach to providing a seamless end-user experience for location-aware applications," in Proc. 1st international workshop on Mobile commerce, July 2001, pp. 20-25.

[7] Chen, J. V., Ross, W., and Huang, S. F., "Privacy, trust, and justice considerations for location-based mobile telecommunication services," info, vol. 10, no. 4, pp. 30-45, 2008.

[8] Wicker, S. B., "The loss of location privacy in the cellular age," Communications of the ACM, vol. 55, no. 8, pp. 60-68, 2012.

[9] Shin, K. G., Ju, X., Chen, Z., and Hu, X., "Privacy protection for users of location-based services," Wireless Communications, IEEE, vol. 19, no. 1 , pp. 30-39, 2012.

[10] Rao, B., and Minakakis, L., "Evolution of mobile location-based services," Communications of the ACM, vol. 46, no. 12, pp. 61-65, 2003.

[11] Choi, S.S. and Choi, M. K., "Consumer's Privacy Concerns and Willingness to Provide Personal Information in Location-Based Services," Advanced Communication Technology, The $9^{\text {th }}$ International Conference, vol. 3, no. 3, pp. 2196-2199, 12-14 Feb 2007.

[12] Godin, S., Permission Marketing, New York: Simon \& Schuster, 1999.

[13] Pavlou, P. A., "State of the information privacy literature: where are we now and where should we go," MIS Quarterly, vol. 35, no. 4, pp. 977-988, 2011
[14] Smith, H. J., Milberg, S. J., and Burke, S. J., "Information privacy: measuring individuals' concerns about organizational practices," MIS quarterly, vol. 20, no. 2, pp.167-196, 1996.

[15] Stewart, K. A., and Segars, A. H., "An empirical examination of the concern for information privacy instrument," Information Systems Research, vol. 13, no. 1, pp. 36-49, 2002.

[16] Smith, H. J., Dinev, T., and Xu, H., "Information privacy research: An interdisciplinary review," MIS quarterly, vol. 3, no. 4, pp. 989-1016, 2011.

[17] Li, Y., "Theories in online information privacy research: A critical review and an integrated framework," Decision Support Systems. Vol. 54, no. 1, pp. 471-481,Dec 2012.

[18] Benbasat, I., and Dexter, A. S., "Individual differences in the use of decision support aids," Journal of Accounting Research, vol. 20, no. 1, pp. 1-11, 1982 .

[19] Maddux, J. E., and Rogers, R. W., "Protection motivation and self-efficacy: A revised theory of fear appeals and attitude change," Journal of Experimental Social Psychology, vol. 19, no. 5, pp. 469-479, 1983.

[20] Hirsh, J. B., Kang, S. K., and Bodenhausen, G. V., "Personalized Persuasion Tailoring Persuasive Appeals to Recipients' Personality Traits," Psychological science, vol. 23, no. 6, pp. 578-581, 2012.

[21] Lu, H. P., Hsu, C. L., and Hsu, H. Y., "An empirical study of the effect of perceived risk upon intention to use online applications," Information Management \& Computer Security, vol. 13 , no. 2 , pp. 106-120, 2005.

[22] Giovanis, A. N., Binioris, S., and Polychronopoulos, G., "An extension of TAM model with IDT and security/privacy risk in the adoption of internet banking services in Greece," EuroMed Journal of Business, vol. 7, no. 1, pp. 24-53, 2012.

[23] Xu, H., Luo, X., Carrol, J. M., and Rosson, M. B., "The personalization privacy paradox: An exploratory study of decision making process for location-aware marketing," Decision Support Systems, vol. 51, no. 1, pp. 42-52, 2011.

[24] Bélanger, F., and Crossler, R. E., "Privacy in the digital age: a review of information privacy research in information systems," MIS Quarterly, vol. 3, no. 4, pp. 1017-1042, 2011.

[25] Ratnasingham, P., "Internet-based EDI Trust and Security", Information Management \& Computer Security, vol. 6, no. 1, pp 33-40, 1998.

[26] Malhotra, N. K., Kim, S. S., and Agarwal, J., "Internet users' information privacy concerns (IUIPC): the construct, the scale, and a causal model," Information Systems Research, vol. 15, no. 4, pp. 336-355, 2004.

[27] Tsao, W. C., and Chang, H. R., "Exploring the impact of personality traits on online shopping behavior," Afr. J. Bus. Manage, vol. 4, no. 9, pp. 1800-1812, 2010.

[28] Limbu, Y. B., Wolf, M., and Lunsford, D. L., "Consumers' perceptions of online ethics and its effects on satisfaction and loyalty," Journal of Research in Interactive Marketing, vol. 5, no. 1, 71-89, 2011.

[29] Nunnally, J. C. (1978). Psychometric theory (2 ${ }^{\text {nd }}$ ed.), New York: Mc-Graw Hill, 1978

[30] Hair, J. F. J., Anderson, R. E., Tatham, R. L., \& Black, W. C. Multivariate data analysis, Upper Saddle River, NJ: Prentice Hall, 1998.

[31] Hoyle, R. H. Structural Equation Modeling: Concepts, Issues, and Application, Thousand Oaks, CA: Sage, pp. 16-36, 1995.

[32] Phelps, J. E., Nowak, G. and Ferrell, E., "Privacy Concerns and Consumer Willingness to Provide Personal Information," Journal of Public Policy and Marketing, vol. 19, no. 1, pp. 27-41, 2000.

[33] Zhou, T., "An empirical examination of user adoption of location-based services," Electronic Commerce Research, vol. 13, no. 1, pp. 25-39, 2013.

[34] Margulis, S. T., "Privacy as a social issue and behavioral concept," Journal of Social Issues, vol. 5, no. 2, pp. 243-261, 2003.

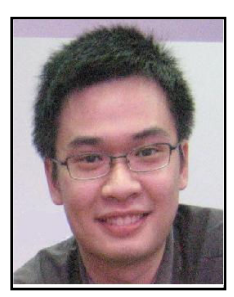

Mr. Soo Shen Hin graduated with First Class (Honours) in Business Management, achieving the outstanding academic scholarship award. $\mathrm{He}$ is currently involved in general mobility consultation, human resource management and cross-cultural communications. He provides full client servicing and support, documentation and database management across an international portfolio of stakeholders. His research interests lie in the evolving nature of management, cross-channel marketing, leadership and personal development as well as talent management. 


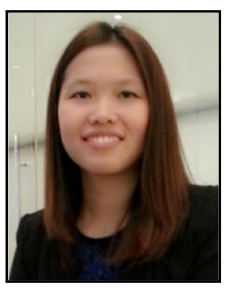

Ms. TAN Ka Yen Madeline Tanamal is currently a business associate at New York Business Consultants LLC, USA. She received a first class honours in Bachelor of Science (Hons) Business Management from Sunway University School of Business, Malaysia. She also has a Degree in Fashion Design from Raffles Design Institute, Malaysia. Her team won the MIX (Moneytree Ideas Exchange) Maybank Challenge in Malaysia, a competition to develop a marketing plan in November 2011. Her research interests include areas in entrepreneurship, innovation and sustainability management.

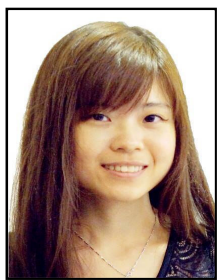

Ms. HO Ju Yi is currently a trade marketing executive in the FMCG Industry, Malaysia. She won the Sin Chew Daily Education Fund scholarship in 2010 and received a Bachelor of Science (Hons) Business Management from Sunway University School of Business, Malaysia. Her research interests include areas in marketing and animal welfare.

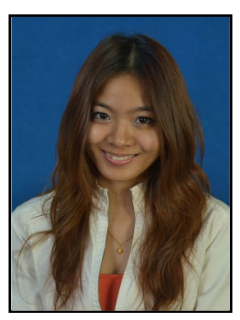

Ms. LOW Wen Ling is currently an account executive in Awan Bina Sdn Bhd, Malaysia. She won the Award of Tan Sri Dato' Seri Dr. Jeffrey Cheah Entrance Scholarship and received a Bachelor of Science (Hons) Business Management from Sunway University School of Business, Malaysia. Her research interests include areas in marketing and consumer behaviour.

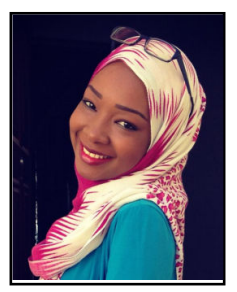

Ms. Maryam Muhammed YAHYA currently works in the management department at Lela industries, Nigeria. She received a Bachelor of Science (Hons) Business Management from Sunway University School of Business, Malaysia. Her research interests include areas in human resource management, international business and entrepreneurship.

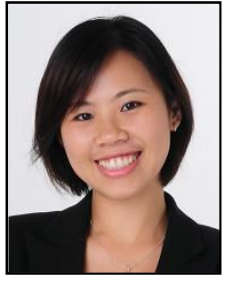

Ms. Jessica Sze Yin HO is currently a lecturer at School of Business, Sunway University, Malaysia. She received her Master of Philosophy in Management and Bachelor of Business Administration majoring in Marketing from Multimedia University, Malaysia (MMU). She is also currently pursuing her $\mathrm{PhD}$ at Multimedia University (MMU). Her research interests include areas in job satisfaction, organizational behavior, service quality, and consumer behavior. Her articles have appeared in International Journal of Business and Management Science; Australian Journal of Basic and Applied Sciences; IEEE International Conference on Industrial Engineering and Engineering Management; and various indexed publications. She is also an associate member of the Malaysia Institute of Management and a member of International Economics Development and Research Centre (IEDRC). 